\title{
Effect of seasonally changing aerial environment on testosterone in Karagouniko and Chios sheep
}

\author{
Aristidis Matsoukis ${ }^{\mathrm{a} *}$ (D) | Aikaterini Chronopoulou-Sereli | George Stratakos
}

aDepartment of Crop Science, Agricultural School of Agricultural Production, Infrastructure and Environment, Agricultural University of Athens, 75 lera Odos St., 11855, Athens, Greece.

*Corresponding author: armatsoukis@aua.gr

\begin{abstract}
A well-established activity in Greece and other Mediterranean countries is sheep farming. Karagouniko and Chios sheep are promising breeds and targets for the reproductive physiologist's attention. Under this context, part of the reproductive physiology of Karagouniko and Chios was investigated, taking into account the environment. Specifically, four time periods were considered; April-June (Long days, increasing photoperiod length), July-September (Long days, decreasing photoperiod length), October-December (Short days, decreasing photoperiod length), and January-March (Short days, increasing photoperiod length). The effect of the period on the concentration of the testosterone (main male hormone) in rams of the breeds above was studied, by using repeated measures analysis of variance, also taking into account the environmental variables air temperature, relative humidity, sunshine, rainfall, and photoperiod, in the Artificial Insemination Center of Karditsa $\left(39^{\circ} 21^{\prime} 18^{\prime \prime} \mathrm{N}, 21^{\circ} 54^{\prime} 19^{\prime \prime} \mathrm{E}\right)$, Greece. The lowering of photoperiod from April-June to JulySeptember (long days) and afterward, even more to October-December (short days) coincided with a progressive increase of testosterone in both breeds. Photoperiod seems to have a major role in the concentration of Karagouniko and Chios breeds' testosterone compared to the other environmental variables. When considering the whole experimental period, Chios sheep had significantly higher $(P<0.05)$ testosterone $(1.95 \mathrm{ng} / \mathrm{ml})$ than the Karagouniko one $(1.55 \mathrm{ng} / \mathrm{ml})$. Our findings could contribute towards the more rational exploitation of the examined sheep breeds.
\end{abstract}

Keywords: air temperature, photoperiod, ram reproductive physiology, repeated measures

\section{Introduction}

Sheep farming provides many advantages in rural areas of Greece and other Mediterranean countries from different perspectives (Tzouramani et al 2019). Karagouniko and Chios promise sheep breeds in the areas mentioned above, with a large part of their potential in their reproductive physiology (Gordon 1997). The main male hormone, testosterone, is of particular interest (Stratakos 2015). Higher concentrations of testosterone for these breeds have been reported in periods with photoperiod less than $12 \mathrm{~h}$ daylight (short days), compared to periods with more than $12 \mathrm{~h}$ daylight (long days) (Rekkas et al 1993; Gundoğan and Demirci 2003).

However, there is a lack in the literature regarding the effect of increasing and decreasing photoperiod length on their testosterone in long and short days. Thus, our current work aims to investigate the response of testosterone of Karagouniko and Chios breeds to the aforementioned photoperiod lengths, taking into account, apart from photoperiod, basic environmental parameters, that is to say, air temperature, relative humidity, sunshine, and rainfall.

\section{Materials and Methods}

\subsection{Ethical approval}

The study protocol was approved by the Ethical Committee of Artificial Insemination Center of Karditsa, Greece.

\subsection{Location and animals}

The research was carried out in the farm of Artificial Insemination Center of Karditsa Municipality $\left(39^{\circ} 21^{\prime} 18^{\prime \prime} \mathrm{N}\right.$, $21^{0} 54^{\prime} 19^{\prime \prime} \mathrm{E}$, altitude of $110 \mathrm{~m}$ above mean sea level), Periphery of Thessaly, Greece, from April to March. Six rams (Ovis aries L.) of Karagouniko sheep breed and another six rams of Chios sheep breed were the experimental material. All animals were fed on a balanced diet based on their nutritional needs, which resulted in their good nutritional status and health. Pertinent details are reported in Matsoukis et al (2019).

\subsection{Collection of environmental data}

Two sensors [Hobo type Pro, H08-032-08, USA, accuracy $\pm 0.2{ }^{\circ} \mathrm{C}$ at $25^{\circ} \mathrm{C}$ for air temperature (AIRT) and $\pm 3 \%$ over $0{ }^{\circ} \mathrm{C}$ to $50{ }^{\circ} \mathrm{C}$ for relative humidity $(\mathrm{RH})$ ], each one connected to a data logger, were used to record AIRT and RH (Chronopoulos et al 2012) every $6 \mathrm{~min}$, during the whole experimental period. Details regarding the specific location and the calibration of the devices involved are reported in Matsoukis et al (2019). Sunshine (SUNS) and rainfall (RNFL) 
data were provided by the meteorological station of the Tobacco Station of Agricultural Research, adjacent to the farm. Photoperiod (РНОTO) was calculated from the time between sunrise and sunset at the experimental farm.

\subsection{Testosterone estimation}

Starting from May, blood samples were taken once a month (on its first day), except March (last month of the experiment), where the collection of blood samples took place twice (on its first and last days), from the jugular vein of each ram between 09h00min and 09h30min (in total 144 blood samples). The blood was collected in individual tubes and immediately placed in a cooler. The blood was then transported to the laboratory, centrifuged, and the serum obtained was frozen at $-20^{\circ} \mathrm{C}$ until testosterone was assayed (Belkadi et al 2017). Testosterone was estimated by radioimmunoassay (RIA) method using a commercial kit (TESTO, RIA, CT, KIP1709, DIAsource ImmunoAssays S.A., Belgium) with an assay range from $0.1 \mathrm{ng} / \mathrm{ml}$ to $17 \mathrm{ng} / \mathrm{ml}$ and sensitivity $0.05 \mathrm{ng} / \mathrm{ml}$ (Kozioł and Koziorowski 2013).

\subsection{Statistical analysis}

For the investigation of the season on each sheep breed, in terms of photoperiod, at first, two time periods were considered; long days (LD), from April to September (>12 h daylight) and short days (SD), from October to March (<12 h daylight).

Then, each one of the aforementioned periods was divided into two smaller periods, totally four periods, for a more detailed view of the photoperiodic environment; long days comprised the periods April-June, named Long daysFirst period, LD1 (increasing photoperiod length) and JulySeptember, named Long days-Second period, LD2 (decreasing photoperiod length) and short days comprised the periods October-December, named Short days - Third period, SD3 (decreasing photoperiod length) and JanuaryMarch, named Short days - Fourth period, SD4 (increasing photoperiod length).

Averages on seasonal basis of the recorded and provided environmental data were estimated. Also, data from the examined variable of sheep (testosterone concentration) were pooled into the four periods above. The two (out of eighteen) extreme means of the variable mentioned above for each breed and period were excluded from the data before the analysis to prevent undue influence of extreme values (Feldman et al 2002).

The experiment was conducted according to the oneway repeated measures design, separately for each sheep breed. Four time periods (April-June, July-September, October-December, January-March) were considered, and paired t-tests were used for pairwise comparison of means by using the Bonferroni correction (Verma 2016).

Also, to investigate possible differences in testosterone concentration between the two sheep breeds, independent t-tests were applied (Kim 2015). Statistics were performed using MS Excel 2010 and IBM SPSS Statistics 23
(Kamoutsis et al 2018), with results considered significant when $P \leq 0.05$.

\section{Results and Discussion}

The mean seasonal values of AIRT, RH, SUNS and PHOTO and the total seasonal RNFL in the experimental area are shown in Figure 1. Photoperiod ranged from $10.31 \mathrm{~h}$ (SD3) to $14.06 \mathrm{~h}$ (LD1), with LD2 and SD4 characterized by $13.51 \mathrm{~h}$ and $10.89 \mathrm{~h}$, respectively. Air temperature ranged from 7.1 ${ }^{\circ} \mathrm{C}$ (SD4) to $26.4^{\circ} \mathrm{C}$ (LD2), with LD1 being warmer than SD3 by $10.3^{\circ} \mathrm{C}$. Relative humidity took its highest $(81.9 \%)$ and lowest values (61\%) at SD3 and LD1 (almost equal to LD2), respectively. The most ( $8.83 \mathrm{~h}$ of SUNS) and least sunny (4.32 $h$ of SUNS) periods were LD2 and SD3 (almost equal to SD4), respectively. The total seasonal RNFL was maximum and lowest at SD3 (248.8 mm) and LD1 $(58.7 \mathrm{~mm})$, respectively.

The repeated measures analysis of variance, regarding the testosterone concentration of Karagouniko and Chios sheep in the study's four successive periods (LD1, LD2, SD3 and SD4), showed the existence of significant differences (Table 1).

Testosterone concentration steadily increased from April-June (minimum values), reaching a maximum in October-December, declining afterward in both Karagouniko and Chios (Figure 2). In Karagouniko, the maximum and minimum testosterone values were significantly different from the respective values of the other periods. In Chios, significant differences in testosterone were confirmed between April-June and each of the three other periods. In terms of averages, for short days and long days, separately, a higher testosterone concentration was confirmed in short days, compared to long days, for both Karagouniko (1.90 $\mathrm{ng} / \mathrm{ml}$ in SD and $1.20 \mathrm{ng} / \mathrm{ml}$ in LD) and Chios (2.28 ng/ml in SD and $1.63 \mathrm{ng} / \mathrm{ml}$ in $L D)$. These results are in agreement with the results of other authors who have reported a higher concentration of testosterone in short days, in comparison with long days, for our studied sheep breeds (Rekkas et al 1993) as well as for others (Gundoğan and Demirci 2003; Aguirre et al 2007).

In our experiment, the isolation of the effects of AIRT, $\mathrm{RH}, \mathrm{SUNS}$, and RNFL from those of PHOTO on testosterone concentration was impossible, irrespective of sheep breed. However, it has been reported that the concentration of testosterone is related noticeably with the reproduction of the examined breeds (Rekkas et al 1993; Stratakos 2015) and that high values of testosterone were obtained in the sheep breeding period (Gündoğan et al 2003b). In addition, PHOTO is considered as a predominant factor, regulating ram reproduction in temperate climate regions (Ortavant et al 1988; Carvajal-Serna et al 2019), like ours. From the reasoning above, the hypothesis of the major role of the PHOTO in the concentration of testosterone of both Karagouniko and Chios seems logical. Also, AIRT has been reported to play a role on sheep reproductive activity (Gündoğan et al 2003a) and, consequently, on the concentration of testosterone, while for the other environmental parameters (RH, SUNS, and RNFL), to our 
knowledge, there are no comparative studies from the literature that measure their impact on testosterone concentration of sheep.

The comparison of Karagouniko and Chios sheep in each period, separately, concerning the testosterone concentration, by using independent t-tests, showed significant differences in LD1 (independent t-test value: -6.37 at $P=0.0001$ ) and SD4 periods (independent t-test value: 2.79 at $P=0.01$ ), due possibly to their greater testosterone differences, compared to LD2 and SD3. Nevertheless, after pooling the testosterone data over the whole period, for each breed separately, it was established that the Chios sheep had significantly higher testosterone $(1.95 \mathrm{ng} / \mathrm{ml})$ than the Karagouniko one (independent t-test value: -2.59 at $P=$ 0.011). The higher testosterone concentration of Chios, by $0.4 \mathrm{ng} / \mathrm{ml}$, compared to Karagouniko, could be explained by their different genetic potential, bearing also in mind that a genetic basis for photo responsiveness has been demonstrated (Poulton and Robinson 1987; Gómez-Brunet et al 2012). Our work shed light on the part of the reproductive physiology of Karagouniko and Chios rams adding knowledge towards their more rational exploitation.

Table 1 Analysis of variance for the effects of time on testosterone concentration of Karagouniko and Chios sheep.

\begin{tabular}{|c|c|c|c|c|c|c|c|}
\hline \multicolumn{8}{|c|}{ Testosterone Concentration (ng/ml) } \\
\hline \multicolumn{4}{|c|}{ Karagouniko sheep } & \multicolumn{4}{|c|}{ Chios sheep } \\
\hline & $d f^{a}$ & Mean square & Variance ratio & & $d f^{a}$ & Mean square & Variance ratio \\
\hline Time $^{b}$ & $2.69^{c}$ & 10.67 & $33.27^{* * *}$ & Time $^{b}$ & $1.92^{d}$ & 9.18 & $11.44^{* * *}$ \\
\hline Residual & $40.34^{c}$ & 0.32 & - & Residual & $28.79^{d}$ & 0.80 & - \\
\hline
\end{tabular}

adf: degrees of freedom, bSeason: Period [Long days-First period (increasing photoperiod length), Long days-Second period (decreasing photoperiod length), Short days-Third period (decreasing photoperiod length), Short days-Fourth period (increasing photoperiod length)], 'Corrected df according to Huynh-Feldt approach (estimated value of epsilon: 0.897) following the significance of Maulchy's test of sphericity (Maulchy's W: $0.391, P=0.025$ ), dCorrected df according to Greenhouse-Geisser approach (estimated value of epsilon: 0.640 ) following the significance of Maulchy's test of sphericity (Maulchy's W: $0.208, P=0.001$ ), ${ }^{* * *}$ : significance at $P \leq 0.001$
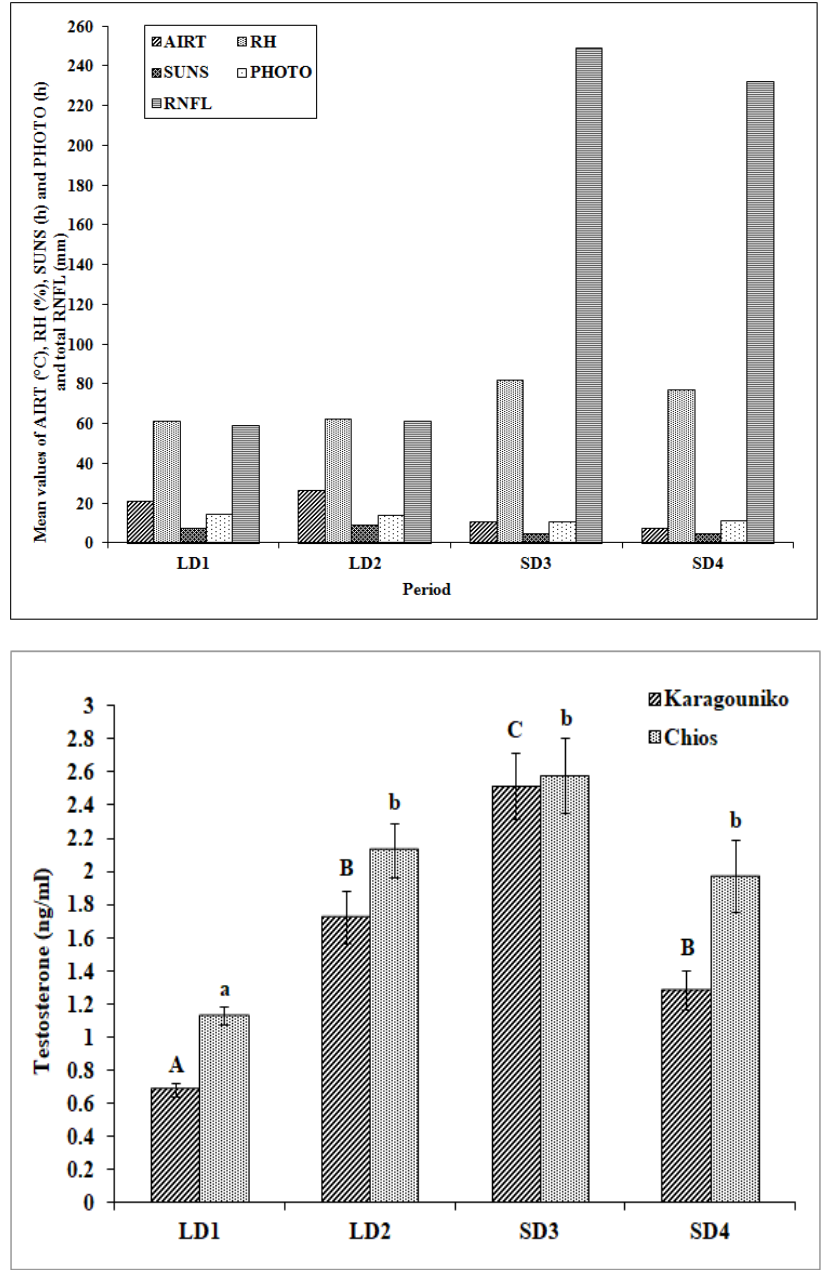

Figure 1 Mean seasonal values of air temperature (AIRT), relative humidity (RH), sunshine (SUNS) and photoperiod (PHOTO), and total seasonal rainfall (RNFL) in the experimental area. LD1: Long days-First period (increasing photoperiod length), LD2: Long days-Second period (decreasing photoperiod length), SD3: Short days-Third period (decreasing photoperiod length), SD4: Short days-Fourth period (increasing photoperiod length).

Figure 2 Effect of season on testosterone concentration of Karagouniko and Chios sheep. In each column, the bar on it represents the standard error of the mean $(n=16)$. Different letters above columns indicate significant differences between the respective means, separately for Karagouniko sheep (upper case letters) and Chios sheep (lower case letters) at $P \leq 0.05$ after Bonferroni correction. LD1: Long days-First period (increasing photoperiod length), LD2: Long daysSecond period (decreasing photoperiod length), SD3: Short days-Third period (decreasing photoperiod length), SD4: Short days-Fourth period (increasing photoperiod length). 


\section{Conclusions}

To sum up, short days resulted in higher testosterone concentration in Karagouniko and Chios sheep (on average) than long days. The lowering of photoperiod from April-June to July-September (long days), and afterward, even more to October-December (short days, decreasing photoperiod length) coincided with a progressive increase of testosterone in both breeds. Chios sheep had higher testosterone concentration than the Karagouniko one when considering the whole experimental period.

\section{Conflict of Interest}

The authors declare that there is no conflict of interest.

\section{Funding}

Thanks are due to the State Scholarships Foundation of Greece, which partly funded the research for this work.

\section{References}

Aguirre V, Orihuela A, Vázquez R (2007) Effect of semen collection frequency on seasonal variation in sexual behaviour, testosterone, testicular size and semen characteristics of tropical hair rams (Ovis aries). Tropical Animal Health and Production. doi: 10.1007/s11250-007-9010-8

Belkadi S, Safsaf B, Heleili N, Tlidjane M, Belkacem L, Oucheriah Y (2017) Seasonal influence of sperm parameters, scrotal measurements, and serum testosterone in Ouled Djellal breed rams in Algeria. Veterinary World. doi 10.14202/vetworld.2017.1486-1492

Carvajal-Serna M, Torres-Ruda F, Cardozo JA, Grajales-Lombana H, CebriánPérez JA, Muiño-Blanco T, Pérez-Pé R, Casao A (2019) Changes in melatonin concentrations in seminal plasma are not correlated with testosterone or antioxidant enzyme activity when rams are located in areas with an equatorial photoperiod. Animal Reproduction Science. doi: 10.1016/j.anireprosci.2018.11.007

Chronopoulos KI, Kamoutsis AP, Matsoukis AS (2012) Thermal comfort estimation in relation to different orientation in mountainous regions in Greece by using artificial neural networks. Global NEST Journal. doi: 10.30955/gnj.000743

Feldman $\mathrm{HA}$, Longcope $C$, Derby $C A$, Johannes $C B$, Araujo $A B$, Coviello $A D$, Bremner WJ, McKinlay JB (2002) Age trends in the level of serum testosterone and other hormones in middle-aged men: Longitudinal results from the Massachusetts male aging study. The Journal of Clinical Endocrinology \& Metabolism. doi: 10.1210/jcem.87.2.8201

Gómez-Brunet A, Santiago-Moreno J, Toledano-Diaz A, López-Sebastián A (2012) Reproductive seasonality and its control in Spanish sheep and goats. Tropical and Subtropical Agroecosystems 15:47-70.
Gordon I (1997) Controlled reproduction in sheep \& goats. Cabi Publishing, Wallingford, UK.

Gündoğan M, Baki D, Yeni D (2003a) Reproductive seasonality in sheep. Acta Agriculturae Scandinavica, Section A - Animal Science. doi: 10.1080/09064700310014960

Gündoğan M, Demirci E (2003) Monthly changes in some reproductive parameters and in testosterone and thyroxine values of rams throughout one year under continental climate conditions. Deutsche Tierärztliche Wochenschrift 110:450-453.

Gündoğan $M$, Uçar $M$, Tekerli $M$ (2003b) An investigation on the relationships between the morphometric measurements of testes and other spermatological features in the rams maintained in the conditions of Afyon before, during and after the breeding period. Lalahan Hayvancilık Araştırma Enstitüsü Dergisi 43:9-22.

Kamoutsis A, Chronopoulos K, Matsoukis A (2018) Altitude and canopy cover effects on air temperature in a mountainous region of Ionian islands, Greece. Current World Environment. doi: 10.12944/CWE.13.3.03

Kim TK (2015) T test as a parametric statistic. Korean Journal of Anesthesiology. doi: 10.4097/kjae.2015.68.6.540

Kozioł K, Koziorowski M (2013) Steroid hormones in peripheral blood plasma and androgen receptors in testis and epididymis of roe deer male (Capreolus capreolus) during the reproduction season. Small Ruminant Research. doi: 10.1016/j.smallrumres.2013.09.008

Matsoukis A, Stratakos G, Chronopoulou-Sereli A, Tsiros I (2019) Seasonal variation of wool fibre length in Karagouniko and Chios sheep in relation to meteorological factors. Emirates Journal of Food and Agriculture. doi: 10.9755/ejfa.2019.v31.i10.2020

Ortavant R, Bocquier F, Pelletier J, Ravault JP, Thimonier J, Volland-Nail P (1988) Seasonality of reproduction in sheep and its control by photoperiod. Australian Journal of Biological Sciences 41:69-85.

Poulton AL, Robinson TJ (1987) The response of rams and ewes of three breeds to artificial photoperiod. Journal of Reproduction and Fertility. doi: 10.1530/jrf.0.0790609

Rekkas C, Kokolis N, Smokovitis A (1993) Breed and seasonal variation of plasminogen activator activity and plasminogen activator inhibition in spermatozoa and seminal plasma of the ram in correlation with testosterone in the blood. Andrologia. doi: 10.1111/j.1439-0272.1993.tb02690.x

Stratakos G (2015) Microclimatic conditions and reproductive physiology of sheep. Dissertation, Agricultural University of Athens, Greece.

Tzouramani I, Zelovitis J, Intxaurrandieta JM, Eguinoa P (2019) Sustainability of dairy sheep farming: Examples from Greece and Spain. In : Ruiz R, LópezFrancos A., López Marco L. (eds) Options Méditerranéennes, A, no. 123Innovations for Sustainability in Sheep and Goats. CIHEAM, Zaragoza, Spain, pp 457-461.

Verma JP (2016) Repeated measures design for empirical researchers. Wiley, Hoboken, New Jersey. 